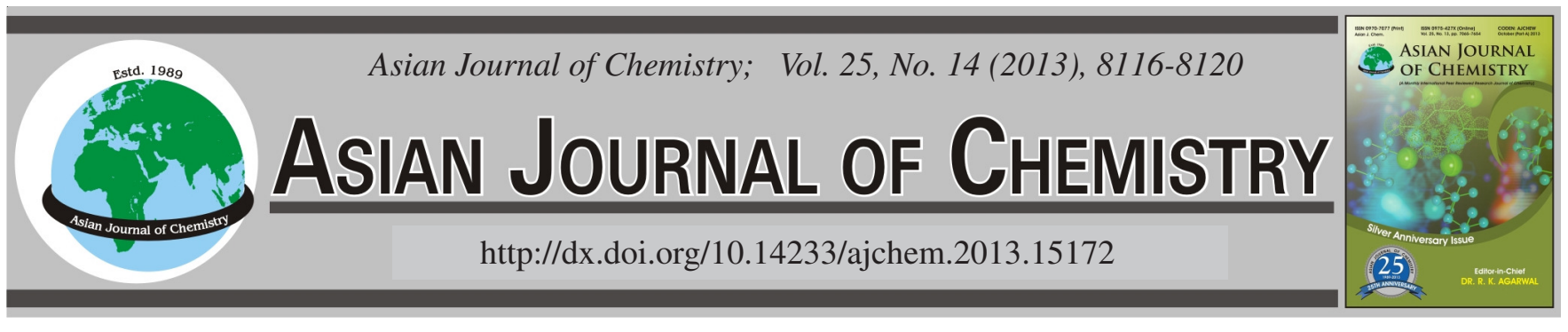

\title{
Impact of Physical Properties and Chemical Composition of Limestone on Decomposition Activation Energy
}

\begin{abstract}
ÖZEN KILIÇ
Department of Mining Engineering, Faculty of Engineering-Architecture, University of Cukurova, 01330 Balcali-Adana, Turkey

Corresponding author: Fax: +90 322 3386126; Tel: +90 322 3386503; E-mail: zenkilic@cu.edu.tr

The aim of this study is to evaluate the effect of chemical composition and physical properties of limestone on bulk density, apparent
porosity, water absorption rate and P-wave velocity, on the activation energy required for its decomposition process. The activation energy
of calcination of spherical particles was calculated from the Arrhenius equation. The samples were calcined by TG-DTA at a temperature
range of $25-1000{ }^{\circ} \mathrm{C}$ and gradient of $10^{\circ} \mathrm{C} / \mathrm{min}$. Samples with higher $\% \mathrm{CaCO}_{3}$ content and $\mathrm{P}$-wave velocity and lower bulk density and
porosity show relatively higher activation energy and rate of lime crystallite growth. This is due to the original grain channel pores and the
formation of triple junction fractures during calcination, which facilitate transfer of hot gases and diffusivity of the evolved $\mathrm{CO}_{2}$. It is
finally concluded that the decomposition of limestone is a temperature, chemical and physical properties dependent process.

Key Words: Limestone properties, Thermal decomposition, Activation energy, TG-DTA.
\end{abstract}

\section{INTRODUCTION}

In broad sense definition, the limestone is any rock rich in $\mathrm{CaCO}_{3}$. Limestone can be obtained from a variety of sources and various limestones differ considerably in their chemical compositions and physical structure. The chemical and physical properties of carbonate rocks are interdependent. Physical characteristics of limestone play an important role in evaluating a deposit. Certain physical characteristics in limestones may indicate a general disposition description during calcination. However, all stones with these characteristics will not decrepitate. Limestones display the following attributes or conditions, alone or in combination, are prone to decrepitation; coarse crystallinity, friability, foliation, excessive calcite veining, microfracturing, highly porous and thinly bedded. The chemical reactivity of different limestones shows a large variation due to their differences in crystalline structure and the nature of impurities such as silica, iron, magnesium, manganese, sodium and potassium. Magnesium and ferrous iron cations occurring in limestone may change the carbonate mineralogy of limestone as well as its physical characteristics such as colour, brightness, specific gravity, hardness, tenacity and decomposition properties ${ }^{1,2}$.

The main chemical property of limestone is its thermal decomposition, known as calcination, during which lime $(\mathrm{CaO})$ and carbon dioxide are produced (eqn. 1) 1,3 $^{1,}$ The calcination process is explained with a partly decomposed piece of carbonate
(Fig. 1). A core model is established to simulate limestone decomposition process, which consists of four sub-processes (Fig. 1) i.e., heat transfer from ambient to particle surface (a), heat conduction from surface to reaction front (b), chemical kinetics at front, diffusion of the $\mathrm{CO}_{2}$ through the porous oxide layer to surface (c-d) and then transfer into ambient.
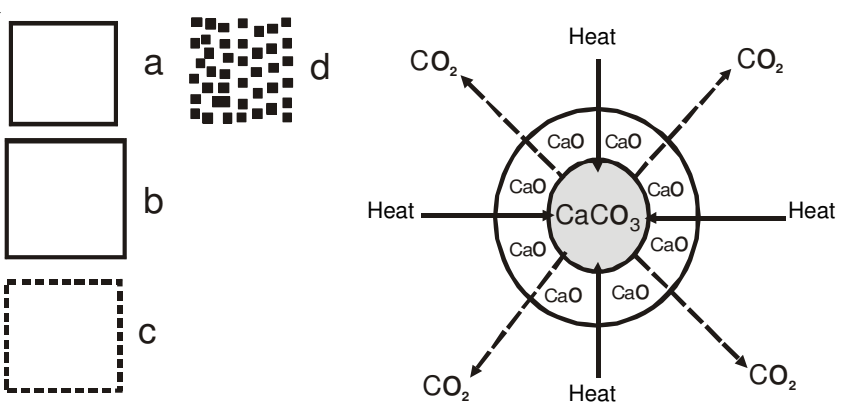

Fig. 1. Model of the decomposition of limestone

The calcination reaction is endothermic

$$
\mathrm{CaCO}_{3} \rightarrow \mathrm{CaO}+\mathrm{CO}_{2} \quad \Delta \mathrm{H}=182.1 \mathrm{~kJ} \mathrm{~mol}^{-1}
$$

which means that the forward reaction is favoured by higher temperatures. The reaction will proceed only if the partial pressure of $\mathrm{CO}_{2}$ in the gas above the solid surface is less than the decomposition pressure of the $\mathrm{CaCO}_{3}$. The latter pressure is determined by equilibrium thermodynamic considerations ${ }^{4}$. 
The activation energy in solid-state reactions can be calculated from Arrhenius equation. In the case of calcination of spherical particles, eqn. 1 can be used for the calculation of the main parameters determining the kinetics of decomposition processes (eqn. 2): $\mathrm{k}$ is the rate coefficient, $\mathrm{A}$ is a constant, $\mathrm{E}$ is the activation energy, $\mathrm{R}$ is the universal gas constant and $\mathrm{T}$ is the temperature (in degrees Kelvin). $\mathrm{R}$ has the value of $8.314 \times$ $10^{-3} \mathrm{~kJ} \mathrm{~mol}^{-1} \mathrm{~K}^{-1}$, entering the Arrhenius equation (eqn. 2):

$$
\mathrm{k}=\mathrm{A} \exp \left(-\frac{\mathrm{E}}{\mathrm{RT}}\right)
$$

In the evaluation of the kinetics of calcination is shown to complicate by $\mathrm{CO}_{2}$ concentration, which inhibits the reaction; particle size, which may introduce both thermal and mass transfer limitations and catalysis/inhibition by impurities. When calcination takes place (eqn. 1), the product calcium oxide weighs only $56 \%$ of the parent carbonate. Since the relative molar volumes are $36.9 \mathrm{~cm}^{3} \mathrm{~mol}^{-1}$ for $\mathrm{CaCO}_{3}$ and 16.9 $\mathrm{cm}^{3} \mathrm{~mol}^{-1}$ for $\mathrm{CaO}$, if there is negligible particle shrinkage, the porosity of the product from a pure non-porous carbonate will increase to a theoretical value of 0.55 . Hence a lime may have a porosity greater than 0.6. For maximum adsorption efficiency, care must be taken on the one hand to ensure that calcination is complete and on the other that the $\mathrm{CaO}$ grains formed do not sinter after formation.

The reaction (eqn. 1) only begins when the temperature is above the dissociation temperature of the carbonates in the limestone. According to Boynton ${ }^{1}$, the $\mathrm{CaCO}_{3}$ decomposition temperature determined by several reserchers at the beginning of the $20^{\text {th }}$ century is generally accepted as $898^{\circ} \mathrm{C}$ at $1 \mathrm{~atm}$ in a $100 \% \mathrm{CO}_{2}$ environment. However, according to some studies, this temperature is $902.5^{\circ} \mathrm{C}^{5-7}$. Kilic ${ }^{8}$ reported that the weight loss above $600{ }^{\circ} \mathrm{C}$, measured by DTA-TG in azot atmosphere, is attributed to the $\mathrm{CO}_{2}$ from the decomposition of calcium carbonate that is initiated at $682-691{ }^{\circ} \mathrm{C}$ and completed at $944-961^{\circ} \mathrm{C}$.

The internal structure of a rock having open and closed pores in its texture affects its heat transfer. The specimen comprises a dense carbonate core surrounded by porous oxide layer. The changes in pore structure also play a significant role on the calcination/heat treatment mechanism and the reactivity of a calcined limestone is strongly dependent on its chemical, physical and structural properties, which in turn are highly dependent on heat treatment conditions ${ }^{9,10}$. In the good calcination process, limestone should be approximately consisting of $97 \% \mathrm{CaCO}_{3}$ and low impurities. Impurities such as iron, magnesium and aluminum oxides tend to lead to lower surface areas in both the limestones and their calcines ${ }^{11}$.

Limestone calcination is a reaction requiring considerable input of energy. Calcination of calcium carbonate is a highly endothermic reaction, requiring $3.16 \mathrm{GJ}(754753 \mathrm{kcal})$ of heat input to produce a tonne of lime $(\mathrm{CaO})^{12}$. To optimize the calcination process in order to save energy and ensure product quality, the decomposition behaviour of individual pieces of carbonate under given process conditions must be known.

The current demand of limestone and its product; lime, worldwide has necessitated investigation into chemical composition and physical properties on the thermal damage. In this paper, the effect of chemical composition and physical properties of limestone on the thermal decomposition was studied, depending on decomposition temperature and activation energy of calcium carbonate. Also, energy is a very important and expensive main input for decomposition system and it must be protect for environmental policy.

\section{EXPERIMENTAL}

The limestones were taken from different large commercial deposits i.e., from Karaisali region $\left(\mathrm{L}_{\mathrm{k}}\right)$ and Yilankale region $\left(\mathrm{L}_{\mathrm{y}}\right)$ in Adana, Turkey. During sampling, rock types having no bedding planes were selected to eliminate any anisotropic effects in the measurements of the samples. Limestones present macroscopically different characteristics. $\mathrm{L}_{\mathrm{k}}$ is a 'dirty white' and light coloured grey limestone comprising discrete and tiny crystals. $\mathrm{L}_{\mathrm{y}}$ is light-coloured 'dirty white' any distinguished crystals. Microcracks were not present throughout the mass of $\mathrm{L}_{\mathrm{k}}$ limestones, but microcracks, dense vein system and schistosity were observed throughout the mass of $\mathrm{L}_{\mathrm{y}}$ limestones.

Analytical methods and techniques: Analyses were performed on limestone samples by using the following analytical procedure. In the chemical analysis and thermal experiments (TG-DTA analysis), ground $-0.5 \mathrm{~mm}$ size limestones were used. Cubic specimens of $5 \mathrm{~cm}$ mean edges (average value $5.11 \pm 0.09)$ and core specimens $(42 \mathrm{~mm} \times 85 \mathrm{~mm}$ cylindrical) were prepared for the physical experiments.

- XRF (Siemens SRS 300 X-ray Flouresans Spectrometer) was used to determine the chemical compositions of limestone samples.

Physical properties (the bulk density, effective porosity, water absorption rate) of the limestones were determined using saturation and buoyancy techniques, as recomended by ISRM and $\mathrm{TSE}^{13}$.

- P-wave velocities were measured by the Pundit instrument (CNS Farnel Pundit Plus C-Portable Untrasonic NonDestructive Indicator Tester), which has two transducers (a transmitter and a receiver) having a frequency of $54 \mathrm{kHz}$.

- Differential thermal and thermogravimetric analyses (simultaneous TG/DTA, Setaram 92 16 DTA-TG) were carried out to determine quantitatively and qualitatively the various compounds presented in samples. Analyses were performed in samples of limestone azot atmosphere at a temperature range of $25-1000^{\circ} \mathrm{C}$ and gradient of $10^{\circ} \mathrm{C} / \mathrm{min}$.

\section{RESULTS AND DISCUSSION}

The chemical analyses results of limestone samples are presented in Table-1. It was found that the studied limestones are very pure; with an average $\mathrm{CaCO}_{3}$ higher than $97 \%$; the impurities $\left(\mathrm{MgO}, \mathrm{Fe}_{2} \mathrm{O}_{3}, \mathrm{Al}_{2} \mathrm{O}_{3}\right.$ and $\left.\mathrm{SiO}_{2}\right)$ are very low. Since the $\mathrm{MgCO}_{3} / \mathrm{CaCO}_{3}$ ratio varies with the type of limestone, the decomposition temperature does not remain constant and therefore must be determined for every type of limestone.

The physical properties of limestones are presented in Table-2. All limestone samples indicated low values in porosity and water absorption rate (lower than $1 \%$ ). The value of apparent density $\left(>2.55 \mathrm{~g} / \mathrm{cm}^{3}\right)$ was found to be characteristic for a limestone ${ }^{12}$. Comparing the limestones, $\mathrm{L}_{\mathrm{k}}$ demonstrated higher values in porosity. 
TABLE-1

CHEMICAL COMPOSITIONS OF LIMESTONE (\%)

\begin{tabular}{ccccccc}
\hline Sample & $\mathrm{CaO}$ & $\mathrm{MgO}$ & $\mathrm{SiO}_{2}$ & $\mathrm{Fe}_{2} \mathrm{O}_{3}$ & $\mathrm{Al}_{2} \mathrm{O}_{3}$ & Loss of ignition \\
\hline $\mathrm{L}_{\mathrm{k}}$ & $55.13 \pm 0.14$ & $0.44 \pm 0.04$ & $0.34 \pm 0.22$ & $0.08 \pm 0.04$ & $0.07 \pm 0.03$ & $43.95 \pm 0.15$ \\
$\mathrm{~L}_{\mathrm{y}}$ & $54.90 \pm 0.35$ & $0.74 \pm 0.58$ & $0.55 \pm 0.31$ & $0.10 \pm 0.05$ & $0.08 \pm 0.06$ & $43.63 \pm 0.53$ \\
\hline
\end{tabular}

TABLE-2

PHYSICAL PROPERTIES OF THE LIMESTONES

\begin{tabular}{ccccc}
\hline Sample & Bulk density $\left(\mathrm{g} / \mathrm{cm}^{3}\right)$ & Water absorption rate (weight) $(\%)$ & Porosity $(\%)$ & P-Wave velocities $(\mathrm{km} / \mathrm{s})$ \\
\hline $\mathrm{L}_{\mathrm{k}}$ & $2.65 \pm 0.08$ & $0.72 \pm 0.22$ & $0.85 \pm 0.04$ & $5.701 \pm 0.044$ \\
$\mathrm{~L}_{\mathrm{y}}$ & $2.72 \pm 0.12$ & $0.39 \pm 0.09$ & $0.70 \pm 0.16$ & $5.855 \pm 0.063$ \\
\hline
\end{tabular}

The physical properties depend not only on the properties of the individual minerals, but also upon the way in which the minerals are assembled and porosity, vein system and microcracks. The relevant information is given by $\mathrm{P}$-wave velocities, which includes the pores and cracks. Information on the porous nature of rock materials is frequently omitted from physical descriptions, but is required if these descriptions are to be used as a guide to mechanical performance ${ }^{14}$. Bulk density is relevant chemical composition of the limestone. Bulk density increases with increase in $\% \mathrm{MgCO}_{3}$ content.

$\mathrm{P}$ wave velocity was used to determine the changes on the physical properties of the limestone samples. P-wave velocity measurements may be performed by the direct method at room conditions through ultrasonic pulse transmission technique by the Pundit instrument (Fig. 2). Velocity measurements were carried out on the cubic specimens. The test was repeated three times in three perpendicular directions and the mean values were recorded as the P-wave velocity.

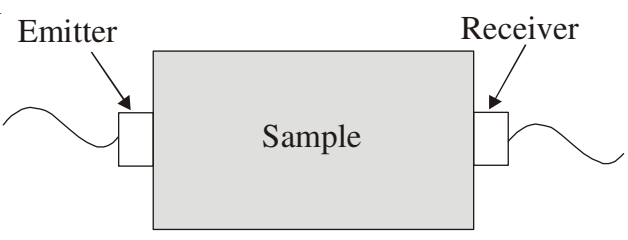

Fig. 2. Method of measuring P-wave velocity

The P-wave velocity, as a natural characteristic of rocks and different materials, depends on their micro- and macrostructure, the existence of minor cracks and porosity and the characteristics of their mineralogical components, such as elastic parameters, density and micro-porosity ${ }^{15}$. Increased velocity with an increase in the dry apparent weight and vice versa is reported by Babuska ${ }^{16}$ and Kopf et al. ${ }^{17}$.

The P-wave velocity in the limestones ranges between 3.500 and $6.500 \mathrm{~km} / \mathrm{s}^{18,19}$; while, for a calcite crystal, the $\mathrm{P}$-wave velocity is $6.490 \mathrm{~km} / \mathrm{s}^{15}$. In the tests, the P-wave velocity in $\mathrm{L}_{\mathrm{k}}$ and $\mathrm{L}_{\mathrm{y}}$ was measured as $5.701 \pm 0.044$ and 5.855 $\pm 0.063 \mathrm{~km} / \mathrm{s}$, respectively. The P-wave velocity measurement values have showed that all specimens have minor cracks and porosity.

Calcination of calcium carbonate is a highly endothermic reaction, requiring $3.16 \mathrm{GJ}$ of heat input to produce a tonne of lime $(\mathrm{CaO})$. The reaction only begins when the temperature is above the dissociation temperature of the carbonates in the limestone. Once the reaction starts the temperature must be maintained above the dissociation temperature and carbon dioxide evolved in the reaction must be removed. Dissociation of the calcium carbonate proceeds gradually from the outer surface of the particle inward and a porous layer of calcium oxide, the desired product, remains.

The differential thermal analysis technique has been used for quantitative determination of heats of decomposition of carbonate materials. It is observed that the carbonates; i.e., limestone, dolomite, have lower heats of decomposition and higher energies of activation in a carbon dioxide atmosphere compared to values obtained in air.

The thermal analysis was performed in a simultaneous TG-DTA. On the limestones, $\mathrm{L}_{\mathrm{k}}$ and $\mathrm{L}_{\mathrm{y}}$, continuous heating from room temperature to $1000{ }^{\circ} \mathrm{C}$ at a heating rate of $10{ }^{\circ} \mathrm{C} /$ min, TG and DTA curves (Figs. 3 and 4) were obtained, is attributed to the $\mathrm{CO}_{2}$ from the decomposition of calcium carbonate.

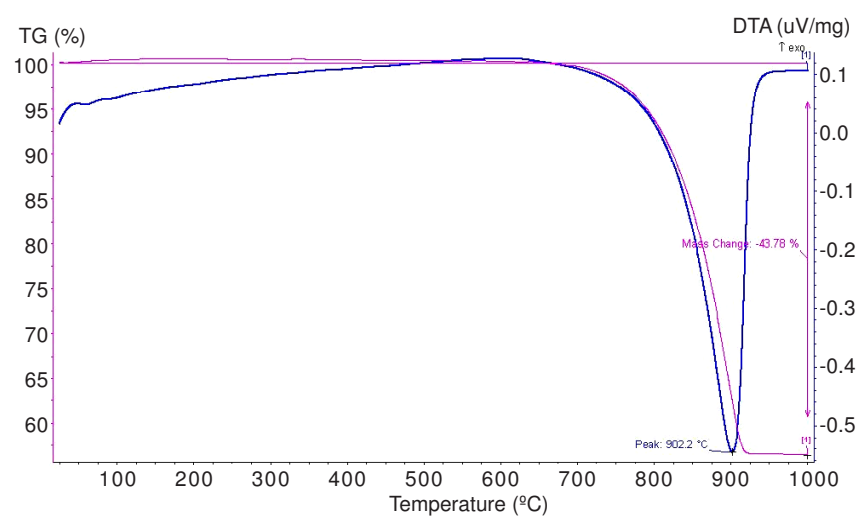

Fig. 3. A thermogram of TG-DTA curve for $\mathrm{L}_{\mathrm{k}}$ decomposition

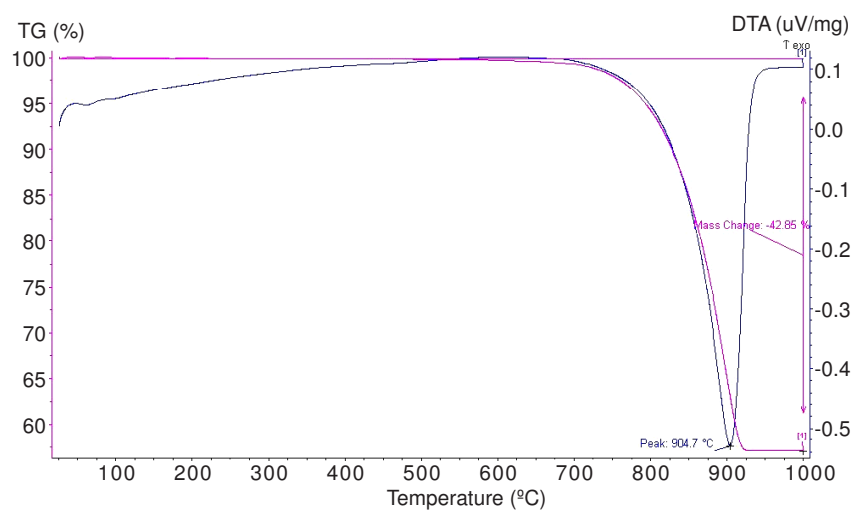

Fig. 4. A thermogram of TG-DTA curve for $\mathrm{L}_{\mathrm{y}}$ decomposition

The figures showed that the weight loss is initiated at 625 and $675^{\circ} \mathrm{C}$ and defined (eqn. 1) fully decomposed approximately at 925 and $935^{\circ} \mathrm{C}$ for $\mathrm{L}_{\mathrm{y}}$ and $\mathrm{L}_{\mathrm{k}}$, respectively. Comparing the percentage values of $\mathrm{CO}_{2}$ measured by DTA/TG, it is 
evident that the values are very high and similar to each other. Thus, the limestones could be characterized as high calcium ones. Furthermore, it is observed that the percentage of $\mathrm{CO}_{2}$ for limestones is higher than the theoretical one.

The figures showed that the weight loss is initiated at 625 and $675^{\circ} \mathrm{C}$ and defined (eqn. 1) fully decomposed approximately at 925 and $935^{\circ} \mathrm{C}$ for $\mathrm{L}_{\mathrm{y}}$ and $\mathrm{L}_{\mathrm{k}}$, respectively. Comparing the percentage values of $\mathrm{CO}_{2}$ measured by DTA/TG, it is evident that the values are very high and similar to each other. Thus, the limestones could be characterized as high calcium ones. Furthermore, it is observed that the percentage of $\mathrm{CO}_{2}$ for limestones is higher than the theoretical one.

The heat treatment experiments have shown that decomposition reaction begins at above $600{ }^{\circ} \mathrm{C}$, corresponding to the loss in carbon dioxide on limestone. The weight losses of the samples were associated $\mathrm{CO}_{2}$ producing in limestone. The specimen comprises a dense carbonate core surrounded by porous oxide layer. During the decomposition/corresponding to the loss in carbon dioxide, micro-cracks and porosity are occurred on limestone (Fig. 1). At higher than $1000^{\circ} \mathrm{C}$, recomposition started, which in turn led to an increase in sample weight. Namely, eqn. 1 initiates to return from right to left ${ }^{8}$.

Calcium oxide is formed during the decomposition/ corresponding to the loss in carbon dioxide (equation). This phenomena is explained with activation energy value. The value of the activation energy show that limestone has $\mathrm{CaCO}_{3}$ ratio and compact structure or micro-crack. Activation energy values were calculated by an Arrhenius equation from DTA-TG curves (Figs. 3 and 4)/data (Tables 3 and 4 and Figs. 5 and 6).

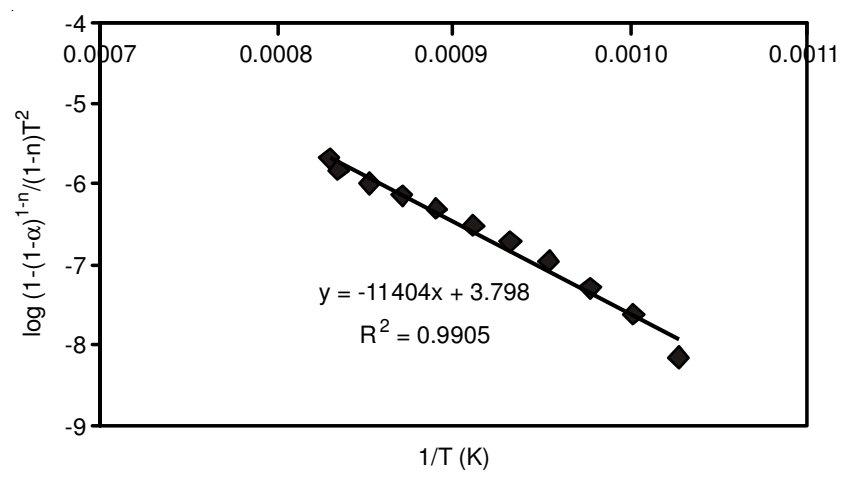

Fig. 5. Graph is used for calculation of activation energy, $L_{k}$

\begin{tabular}{ccccc}
\multicolumn{5}{c}{ TABLE-3 } \\
\multicolumn{5}{c}{$\begin{array}{c}\text { KINETIC ANALYSIS OF L } \mathrm{L}_{\mathrm{k}} \text { AT A HEATING RATE OF } \\
10^{\circ} \mathrm{C} / \mathrm{min} \text { ACCORDING TO COATS REDFERN }\end{array}$} \\
\hline $\begin{array}{c}\text { Temp. } \\
\left({ }^{\circ} \mathrm{C}\right)\end{array}$ & $\mathrm{TG}(\%)$ & $\alpha=\frac{\mathrm{w}_{\mathrm{o}}-\mathrm{w}_{\mathrm{t}}}{\mathrm{w}_{\mathrm{o}}-\mathrm{w}_{\alpha}}$ & $\frac{1-(1-\alpha)^{-\mathrm{n}}}{\mathrm{T}^{2}(1-\mathrm{n})}$ & $\log \frac{1-(1-\alpha)^{1-\mathrm{n}}}{\mathrm{T}^{2}(1-\mathrm{n})}$ \\
\hline 675 & 1.191 & - & - & - \\
700 & 1.065 & 0.00341 & $7.21145 \mathrm{E}-09$ & -8.14198 \\
725 & 0.712 & 0.01169 & $2.35315 \mathrm{E}-08$ & -7.62835 \\
750 & 0.007 & 0.02700 & $5.18599 \mathrm{E}-08$ & -7.28517 \\
775 & -1.271 & 0.06021 & $1.10827 \mathrm{E}-07$ & -6.95536 \\
800 & -3.306 & 0.10834 & $1.91865 \mathrm{E}-07$ & -6.71700 \\
825 & -6.373 & 0.18350 & $3.14721 \mathrm{E}-07$ & -6.50207 \\
850 & -10.761 & 0.28790 & $4.82086 \mathrm{E}-07$ & -6.31688 \\
875 & -17.00 & 0.42539 & $7.03303 \mathrm{E}-07$ & -6.15286 \\
900 & -24.516 & 0.61248 & $1.02179 \mathrm{E}-06$ & -5.99064 \\
925 & -35.400 & 0.84429 & $1.48567 \mathrm{E}-06$ & -5.82808 \\
935 & -41.918 & 1.00000 & $2.06608 \mathrm{E}-06$ & -5.68485 \\
\hline
\end{tabular}

TABLE-4

KINETIC ANALYSIS OF $\mathrm{L}_{\mathrm{y}}$ AT A HEATING RATE OF $10^{\circ} \mathrm{C} / \mathrm{min}$ ACCORDING TO COATS REDFERN ${ }^{4}$

\begin{tabular}{ccccc}
$\begin{array}{c}\text { Temp. } \\
\left({ }^{\circ} \mathrm{C}\right)\end{array}$ & TG $(\%)$ & $\alpha=\frac{\mathrm{w}_{\mathrm{o}}-\mathrm{w}_{\mathrm{t}}}{\mathrm{w}_{\mathrm{o}}-\mathrm{w}_{\alpha}}$ & $\frac{1-(1-\alpha)^{1-\mathrm{n}}}{\mathrm{T}^{2}(1-\mathrm{n})}$ & $\log \frac{1-(1-\alpha)^{1-\mathrm{n}}}{\mathrm{T}^{2}(1-\mathrm{n})}$ \\
\hline 625 & 1.138 & - & - & - \\
650 & 1.108 & 0.0038 & $8.22 \mathrm{E}-09$ & -8.0849 \\
675 & 1.050 & 0.0051 & $1.15 \mathrm{E}-08$ & -7.93973 \\
700 & 0.686 & 0.0104 & $2.21 \mathrm{E}-08$ & -7.65525 \\
725 & 0.007 & 0.0261 & $5.29 \mathrm{E}-08$ & -7.27654 \\
750 & -1.182 & 0.0538 & $1.04 \mathrm{E}-07$ & -6.98184 \\
775 & -3.126 & 0.0988 & $1.84 \mathrm{E}-07$ & -6.73542 \\
800 & -6.126 & 0.1681 & $3.02 \mathrm{E}-07$ & -6.51959 \\
825 & -11.000 & 0.2776 & $4.87 \mathrm{E}-07$ & -6.31234 \\
850 & -17.000 & 0.4275 & $7.42 \mathrm{E}-07$ & -6.12975 \\
875 & -25.000 & 0.6250 & $1.1 \mathrm{E}-06$ & -5.96001 \\
900 & -34.731 & 0.8310 & $1.52 \mathrm{E}-06$ & -5.81878 \\
920 & -42.046 & 0.9998 & $2.11 \mathrm{E}-06$ & -5.67542 \\
925 & -42.053 & 1.0000 & $2.1 \mathrm{E}-06$ & -5.67761 \\
\hline
\end{tabular}

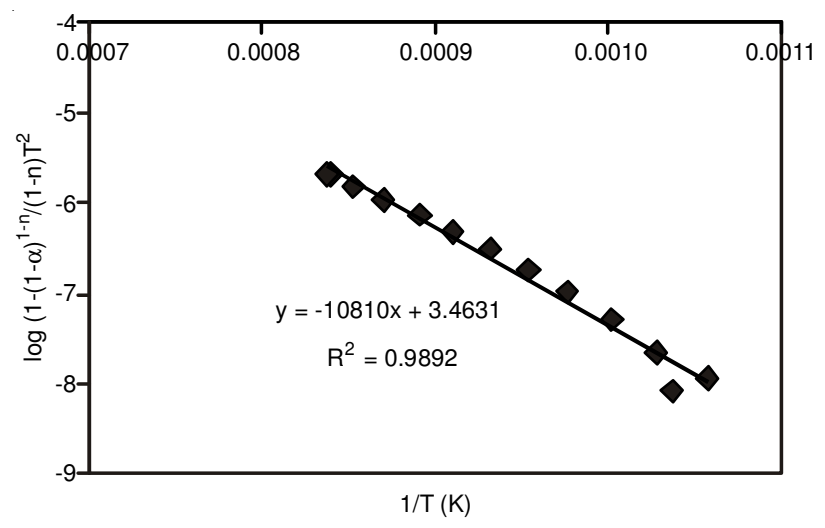

Fig. 6. Graph is used for calculation of activation energy, $L_{y}$

An Arrenius relationship exists for the change in thermal conductivity with temperature and a plot of $\log \kappa_{\mathrm{s}}$ versus $1 / \mathrm{T}$ gives a straight line (Figs. 5 and 6). According to Figs. 5 and 6 , the activation energy values of the limestones were calculated $227.88 \mathrm{~kJ} / \mathrm{mol}(54.43 \mathrm{kcal} / \mathrm{mol})$ and $232.61 \mathrm{~kJ} / \mathrm{mol}(55.56$ $\mathrm{kcal} / \mathrm{mol}$ ) for $\mathrm{L}_{\mathrm{k}}$ and $\mathrm{L}_{\mathrm{y}}$, respectively. The effective values of activation energy were within the range of literature values and were found.

The commonly accepted value for the activation energy of $\mathrm{CaCO}_{3}$ dissociation is $45 \mathrm{kcal} / \mathrm{mole}^{20}$. The activation energy of limestone dissociation varies from $30-60 \mathrm{kcal} / \mathrm{mol}^{21}$. The variation is due to the associated impurities and proportion of calcite in raw material, for example, the presence of impurities like aragonite leads to an increase in the energy barrier for decomposition, while clay minerals reduce the activation energy.

\section{Conclusion}

The study has demonstrated that thermal decomposition of limestone depending on chemical composition, physical properties like decomposition temperature and activation energy of calcium carbonate. The reaction temperature has a direct effect on the conductivity of limestone depending on its impurities, porosity and micro-cracks and hence on the rate of reaction. The reaction rate can be enhanced through improved heat transfer systems. 
Samples with higher $\% \mathrm{CaCO}_{3}$ content and $\mathrm{P}$-wave velocity and lower bulk density and porosity show relatively higher activation energy and rate of lime crystallite growth. This is due to the original grain channel pores and the formation of triple junction fractures during decomposition process, which facilitate transfer of hot gases and diffusivity of the evolved $\mathrm{CO}_{2}$. It is finally concluded that decomposition process of limestone is a temperature, chemical and physical properties dependent process.

The temperature dependent terms were found using Arrhenius law and it was observed that the reaction temperature has a direct effect on the rate of reaction and limestone chemical properties. The effective values of activation energy were all within the range of literature values and were found to be 54.43 and $55.56 \mathrm{kcal} / \mathrm{mol}$ for $\mathrm{L}_{\mathrm{k}}$ and $\mathrm{L}_{\mathrm{y}}$, respectively.

\section{REFERENCES}

1. R.S. Boynton, Chemistry and Technology of Lime and Limestone, John Wiley \& Sons, Inc., New York, edn. 2 (1980)

2. S.T. Krukowski, Lime, Industrial Minerals \& Rocks, Society for Mining Metallurgy and Exploration Inc (SME), USA, edn. 7 (2006).

3. J.A.H. Oates, Lime and Limestone Chemistry and Technology Production and Uses, Wiley-VCH Verlag GmbH, Germany, p. 169 (1998).

4. A.W. Coats and J.P. Redfern, Nature, 201, 68 (1964).

5. T.E. Turkdogan, G.R. Olsson, A.H. Wriedt and S.L. Darken, Trans. Soc. Min. Eng.-AIME, 254, 9 (1973)

6. L.J. Thompson, Pit Quarry, 5, 80 (1979).

7. R.H. Borgwardt, AIChE J., 31, 103 (1985).
8. Ö. Kiliç, Ph.D. Thesis, Comparison of Calcination Parameters of Classic (Eberhart) and Parallel Flow Regenerative Kiln (Maerz) and Applications on Çukurova Region Limestones, Department of Mining Engineering, Institute of Natural and Applied Sciences, University of Çukurova, Adana, p. 171 (2005).

9. J.G. Khinast, G. Krammer, C. Brunner and G. Staudinger, Chem. Eng. Sci., 51, 623 (1996).

10. F. Rubiera, B.A. Faurtes, J.J. Pis, V. Artos and G. Marban, Thermochim. Acta, 179, 125 (1991).

11. A. Trikkel and R. Kuusik, Oil Shale, 4, 491 (2003).

12. B.R. Stanmore and P. Gilot, Fuel Processing Technol., 16, 1707 (2005).

13. TS EN 1097-2, Tests for Mechanical and Physical Properties of Aggregates-Part 2: Methods for the Determination of Resistance to Fragmentation (2010).

14. M.I. Smorodinov, E.A. Motovilov and V.A. Volkov, Determinations of Correlation Relationships Between Strength and Some Physical Characteristics of Rocks. Proceedings of the Second Congress of the International Society of Rock Mechanics, Belgrade, vol. 2, p. 35 (1970).

15. V. Vajdová, R. Prslash ikryl, Z. Pros and K. Klíma, Phys. Earth Planet In, 114, 39 (1999).

16. V. Babuška, Stud. Geph. Geod., 12, 291 (1968).

17. M. Kopf, H.J. Müller and B. Gottesmann, In eds.: A. Kapicka, V. Kropácek and Z. Pros, Correlation Between Pyroxene Content and Vp and Vs Under High Pressure, Physical Properties of the Mineral System of the Earth's Interior. Prague: Union Czech. Math. Phys. (1985).

18. S.D. Parasnis, Principles of Applied Geophysics, London: Chapman \& Hall, p. 429 (1997).

19. Ö. Kiliç, Int. J. Rock Mechanics Mining Sci., 43, 980 (2006).

20. M. Mecarty, V.R. Vernekel Pai and J.W. Maycock, Proc. 3rd. IVTA, 355 (1971).

21. T.K. Chatterjee, A.K. Chatterjee and S.N. Ghosh, Silic, Ind. 45, 81 (1980). 